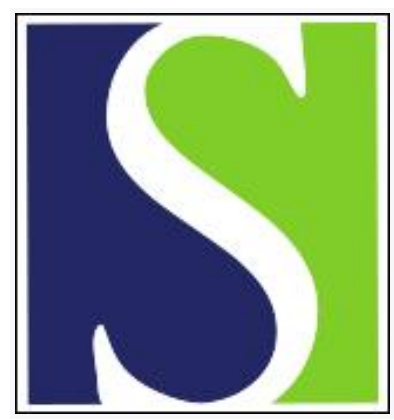

Scand J Work Environ Health 1987;13(5):459

https://doi.org/10.5271/sjweh.2014

Issue date: Oct 1987

Preliminary results on smoking patterns for workers attending an asbestos abatement course.

by Lange JH, Weyel DA, Rosato LM, Tucker D, Malek DE, Mayernik JA, Ryan LK

This article in PubMed: www.ncbi.nlm.nih.gov/pubmed/3433048

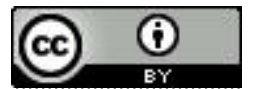




\section{Preliminary results on smoking patterns for workers attending an asbestos abatement course}

Hilt et al (1) have reported information on occupational asbestos exposure and smoking habits. Our information supports theirs and shows an additional occupational group at risk for diseases related to smoking and asbestos exposure.

Recently we have collected information on asbestos abatement workers and their smoking habits. A group of asbestos abatement workers has been created as a result of the demand to remove asbestos from buildings in the United States. The University of Pittsburgh, Graduate School of Public Health, Department of Industrial Environmental Health Sciences, in cooperation with the Allegheny County Health Department (Pittsburgh, PA) has begun to train workers engaged in asbestos abatement projects. This course is a result of the Allegheny County requirement that workers engaged in asbestos removal complete a certification program.

Although other approved courses are available outside the county, workers must, at a minimum, take the asbestos training examination given by the Department of Industrial Environmental Health Sciences, and we have been able to conduct a smoking survey of those attending. During the registration all workers were requested to fill out a smoking survey form. No information was obtained to identify individual participants. Surveys were then deposited by the participants in a labeled box near the entrance of the classroom.

The preliminary results by 10 -year age groups for smokers, former smokers, and never smokers are reported in table 1 . These results are based on questionnaires turned in by participants of the first two training sessions. It is expected that 10 more training sessions will be conducted in 1987 . The two sessions had 133 participants with 120 (114 white males, 4 black males, and 2 white females) returning the survey forms (90\% returned).

The results shown in table 1 , compared with those of a United States general population $(41.4 \%$ current smokers, $28.7 \%$ former smokers, and $29.9 \%$ never smokers - for white males), show that a higher percentage of attendees were smokers, or never smokers, with a lower percentage of former smokers (2). While the data of Hilt et al (those exposed to asbestos) (table 5 , page 562 of their report) report current smokers at $44.7 \%$, ex-smokers at $36.9 \%$, and never smokers at $19.4 \%$. However, our group includes a small number of professional workers (ie, engineers) $(>10 \%)$, which would tend to increase the number of never smokers.
Although asbestos abatement workers are required to use protective equipment, most report that deviations from this standard are common. Some of the workers admit removing respiratory protection in the asbestos abatement work area and engaging smoking and/or eating.

Workers in this industry have reported using respiratory filter cartridges for weeks to months, although regulations require this equipment to be changed after showering, which should be done when the workers exit the abatement area. Since the majority $(>57 \%)$ of the workers attending asbestos abatement training are under 35 years of age, their future rate of lung cancer within the next $10-40$ years could be substantially increased. Therefore, this group should also be considered at high risk and included in lung cancer screening programs.

Table 1. Smoking status of participants in an asbestos training course by age.

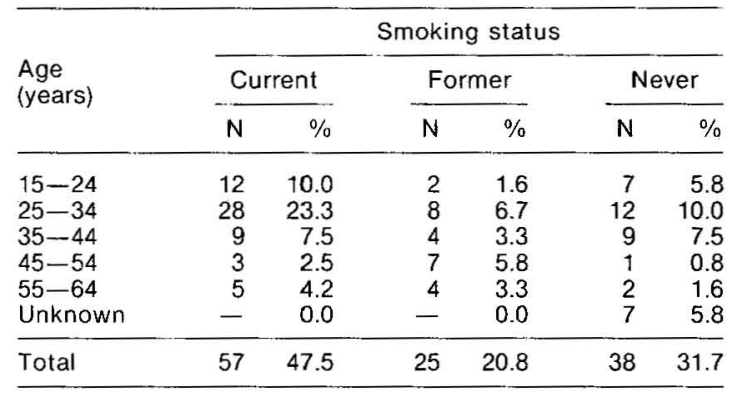

\section{References}

1. Hilt B, Langard S, Lund-Lassan PG, Lien JT. Previous asbestos exposure and smoking habits in the county of Telemark, Norway - A cross sectional population study. Scand J Work Environ Health 12 (1986) $561-566$.

2. Suta BE, Thompson CR. Smoking patterns of motor vehicle industry workers and their impact on lung cancer mortality rates. J Occup Med 25 (1983) 661-667.

John H Lange, Dietrich A Weyel, Laura M Rosato, David Tucker, Dolores E Malek, Janet A Mayernik, Lisa K Ryan

Asbestos Training Program

Department of Industrial Environmental Health Sciences

University of Pittsburgh

Pittsburgh, PA 15261 USA 